\title{
Integrated management of onion pink root rot caused by Setophoma terrestris
}

\author{
Mahmoud E.Y., Zeinab N. Hussien and M.M. Ibrahim
}

Plant Pathology Res. Ins., Agric. Res. Center, Giza., Egypt

Received: 25 Sept. 2020 / Accepted 20 Nov. 2020 / Publication date: 30 Nov. 2020

\begin{abstract}
Due to the high environmental risks of fungicides, biological control of plant diseases with bio-factor are highly encouraged and recommended as well as trying to use natural products such as oils and plant extracts as alternatives to fungicides. Greenhouse and field experiments were conducted in 2017/2018 and 2018/2019 to study the effect of Bacillus subtilis, when applied as soil treatment in combination with different concentrations of essential plant oils as dipping treatment on onion pink rot disease. Oils of cumin, cardamom and thyme were tested at five concentrations $(0.25 \%, 0.50 \%, 1 \%, 2 \%$, and $4 \%)$, on the linear growth of Setophoma (Pyrenochaeta) terrestris isolates. Thyme oil had the strongest inhibitory effect on linear growth followed by cumin oil. Moreover, the reduction of linear growth increased by increasing concentration of the tested essential plant oils. Under artificial and natural infection conditions in greenhouse and field trials, when applying $B$. subtilis with essential plant oils at different concentrations led to significantly effect in reducing incidence of onion pink root rot, compared with untreated control. Also, all tested treatments increased fresh and dry weight under greenhouse conditions as well as increased onion bulb yield in field trials. Data also clearly showed that, there is a positive significant relationship between increase of plant oils concentrations and increase their effect on the incidence of onion pink root rot. Generally, thyme oil at $4 \%$ with $B$. subtilis followed by cumin at $4 \%$ with $B$. subtilis gave the highest percentage of healthy plants as well as the highest efficacy in reducing onion pink root rot compared to other treatments. These results suggest that, one of the means to achieve the goal of sustainable agriculture in controlling of onion pink root rot disease alongside improving onion productivity can be achievement by using of these environmentally safe treatments.
\end{abstract}

Keywords: Pyrenochaeta terrestris, Setophoma terrestris, Bacillus subtilis, bioagent, cumin, thyme, cardamom, biological control, essential plant oils, and integrated control

\section{Introduction}

Onion (Allium cepa L.) is the most widely cultivated Allium species in Egypt producing area 190628 fed. and a production of 2857337 ton as mentioned by the yearly book 2019 of Economics and Statistics of the Economic Affairs Sectors, Agriculture Ministry in Egypt. However, it is susceptible to many diseases, including pink root rot.

Pink root rot disease caused by Setophoma (Pyrenochaeta) terrestris Hansen is one of the most destructive diseases attacking onion in the field causing great damage and losses. The causal organism is soil-borne and remains viable in the soil for many years (Kim, et al., 2003 and Mohamed-Hala 2018).

Biological control of fungal plant pathogens appears as an attractive and realistic approach due to the environmental regulations and the weakness of chemical control. Many numerous of microorganisms have been identified as biocontrol agents, which defined as able to reduction of the amount of inoculum of pathogen (Mishra et al., 2013). Plant growth-promoting rhizobacteria (PGPR) considered one of the most important groups of bioagent and know it as able to suppress a variety of root and vascular disease caused by soil-borne pathogens. Bacillus was considered as an important number of these bacteria and its application under greenhouse and field conditions, reduced dampingoff and root rot and crown rot diseases caused by Rhizoctonia solani, Macrophomina phaseolina and Fusarium oxysporum (El-Hadidy, 2003, Mahmoud, 2014 and Ahmed et al., 2019 and Zhansheng et al., 2019).

Essential oils are concentrated, hydrophobic liquid containing volatile aromatic compounds. They may provide potential alternatives to the control means currently used because of bioactive chemicals (Pawar and Thaker, 2007). They offer a variety of functions for the plants together with (i) 
protecting themselves of heat or cold, (ii) attracting or repelling insects and (iii) using chemical ingredients in the oil as defense equipment. As well, as Essential oils have shown promising results in vitro studies for their antifungal effects on mycelial growth and spore germination against many phyto-pathogenic fungi such as Rhizoctonia solani, Fusarium moniliforme and $F$. oxysporum (Mahmoud, and Gomaa, 2015, Sameza et al., 2016, Thabet and Khalifa 2018 and Omar and Kordali, 2019). Volatiles of many spices such as thyme, cumin and cardamom were proved to be one of the most effective inhibitor of the microbial growth and having a good antibacterial activity with direct contact moreover they have a positive effect on reducing of soil-borne diseases in pots and field trials (EL-Bastawesy and Mohamed 2005, Kapoor et al., 2008, Mahmoud et al., 2013 and Mahmoud and Gomaa 2015). They have biological activities such as antimicrobial activity, this attributed to contain fractions or to sulfur-containing compounds in the aqueous phase, responsible for the aroma and flavor characteristic (El-Moshtohory, 2007).

The present study was conducted to investigate the effect of essential plant oils (as transplant dipping treatment) integrated with Bacillus subtilis (as soil treatment) for the suppression of onion pink root rot.

\section{Materials and Methods}

\section{The fungal isolates}

Isolates of $S$. terrestris were obtained from Beheira (El-Nobaria), Sharkia and Fayoum Governorates. The fungus was isolated from field-grown onion roots with pink-root symptoms. Infected onion plants with prominent pink-root disease symptoms were selected and their roots were first washed in running tap water for $20 \mathrm{~min}$, then cut into small pieces $(0.5-1 \mathrm{~cm})$, soaked in $0.5 \%$ sodium hypochlorite $(10 \%$ Chlorox) for surface sterilization, rewashed in sterilized water and dried between two pieces of sterilized filter paper. Three root pieces were inoculated equidistantly, in each Petri dish containing potato Dextrose Agar medium (PDA). The inoculated plates were incubated at $24^{\circ} \mathrm{C}$ for 4 to7 days.Watson, (1961) technique was used for identification of S. terrestris.

\section{Preparation of fungal inoculum:}

The Inoculum of $S$. terrestris was prepared using sorghum - coarse sand - water $(2: 1: 2 \mathrm{v} / \mathrm{v})$ medium. The ingredients were mixed, bottled and autoclaved at $121^{\circ} \mathrm{C}$ for 60 minutes. Each bottle of sterilized medium was inoculated with $5 \mathrm{~mm}$ fungal growth disc obtained from the periphery of 7-dayold culture of the fungus. The inoculated media were incubated at $24^{\circ} \mathrm{C}$ for 25 days before used for soil infestation.

\section{Soil infestation:}

Fungal propagules of $S$. terrestris (Nobaria isolate) were mixed thoroughly with the surface soil of each pot, at the rate of $0.1 \% \mathrm{w} / \mathrm{w}$, and then covered with a thin layer of sterilized soil. Pots containing infested soil were irrigated and kept for 10 days until sown.

\section{Disease assessment:}

a) The number of plants having typical pink rot symptoms was counted after two and four month from planting and their percentage were calculated according to Hovius and Goldman (2004) as follows:

$$
\begin{aligned}
& \% \text { Pink rot }=\frac{\text { Number of plants infested with pink rot }}{\text { Total No. of plants }} \times 100 \\
& \% \text { Healthy plants }=\frac{\text { Number of survived healthy plants }}{\text { Total No. of plants }} \times 100
\end{aligned}
$$

C) Percent efficacy of treatment in reducing the diseases infection was calculated.

$$
\% \text { Treatment efficiency }=\frac{\text { Control-Treatments }}{\text { Control }} \times 100
$$




\section{Source of antagonistic bacteria:}

Known isolate of Bacillus subtilis; Bs1 (El-Hadidy, 2003) were obtained from Culture Collection of the Department of Plant Pathology, Faculty of Agriculture, Ain Shams University, Cairo, Egypt.

\subsection{Preparation of bacterial inoculum:}

Bacillus isolate was grown on nutrient agar medium, Bacterial suspensions $\left(1 \times 10^{6} \mathrm{cfu} / \mathrm{ml}\right)$ were prepared by dilution plate assay as described by Callan et al., (1990).

\subsection{Methods of bacterial inoculum application:}

The antagonistic bacteria $\left(10^{6} \mathrm{cfu} / \mathrm{ml}\right)$ were applied as a soil drench after 7 (approximately 10 $\mathrm{ml} /$ pore) and 15 days from planting.

\section{Use of plant oils:}

Commercial essential oils of cumin, cardamom and thyme were used in the present work. Essential oils used in the study were obtained from Chemical Industrial Development Company (CID), Egypt.

\subsection{Chemical analysis of essential plant oils tested}

The obtained essential oils were used for GC Mass analyses (Basyony et al., 1989).These analyses carried out at Agricultural Research Center (ARC) Plant Pathology Res. Inst. Biotechnology Unit. Using GC Mass System (Agilent Technologies 5975 Inert XL Mass Selective Detector). The conditions separation was as (Basyony et al., 1989).

\subsection{Effect of different essential plant oils on the linear growth of the pathogen in vitro:}

The inhibitory effect of different concentrations of essential plant oils namely cumin, cardamom and thyme on the in vitro linear growth of $S$. terrestris isolates was evaluated. The agar dilution method were prepared according to Omidbaigi et al., (2007) whereas, different amounts of pure essential oil dissolved in ethanol $(10 \% \mathrm{v} / \mathrm{v}), 0.5 \%$ Tween- 80 to prepared a homogeneous solution of essential plant oil. $10 \mathrm{ml}$ of essential plant oil solution was added to $90 \mathrm{ml}$ PDA media and shaken well to achieve the required concentration of each oil $(0.25,0.50,1,2,4 \%$ and $8 \%)$, then poured into the Petri-dishes $(\varnothing 9$ $\mathrm{cm})$ when the medium was still warm $\left(40^{\circ} \mathrm{C}\right)$. After medium solidification the plates were inoculated with $5 \mathrm{~mm}$ disk of each fungal isolates and incubated at $24{ }^{\circ} \mathrm{C}$. Five plates for each particular treatment were used as replicates. Linear growth was observed daily and diameters of fungal colonies in "mm" were recorded when any of control plates (90 ml PDA plus $10 \mathrm{ml}$ ethanol $(10 \% \mathrm{v} / \mathrm{v})+0.5 \%$ Tween- 80$)$ filled with the fungal growth.

\subsection{Methods of essential plant oils application:}

Different essential plant oils concentrations were prepared by using ethanol $(10 \% \mathrm{v} / \mathrm{v})$, tween 80 $(0.5 \% \mathrm{v} / \mathrm{v})$ as dispersing agent and arabic gum $(0.1 \%)$ as adhesive material and onion transplant were dipped in these preparations for 1 hour then planted in pots and field.

\section{Greenhouse experiments}

Pots $(50 \mathrm{~cm}$-diam) were sterilized by $5.0 \%$ formalin solution for 15 minutes, left to dry for two days to get rid of formalin residues, then filled with soil previously sterilized by formalin solution (5.0\%) for 15 days and left for 15 days. Fungal propagules (Nobaria isolate) were added to the potted soil as mentioned before.

Apparently healthy onion transplants of Giza 20 cultivar were dipped for one hour in essential plant oils concentrations $(0.50,1,2$, and $4 \%)$, then planted rate of 10 transplants per pot. Also, bacterial suspensions were applied as a soil drench at the 7 and 15 days from planting $(100 \mathrm{ml} /$ pot). Experiment was replicated for four times. Disease assessment was recorded as previously mentioned. Also, fresh weight of onion plants from each pot of different treatments were recorded directly after harvest as $\mathrm{g} / \mathrm{pot}$ and dried in an oven at about $70^{\circ} \mathrm{C}$ for two days to obtain the dry weights. 


\section{Field experiments:}

Field experiments were carried out during onion sowing seasons, 2017/2018 and 2018/2019 under naturally infested soil, at El-Nobaria. Randomized complete block design with four replicates was used and the plot was $3.0 \times 3.5 \mathrm{~m}^{2}\left(10.5 \mathrm{~m}^{2}=1 / 400\right.$ fed.). Each plot included 6 rows (each $3.0 \mathrm{~m}$ length and $50 \mathrm{~cm}$ width). Sixty day-old transplants of onion cultivar Giza 20 were dipped for one hour in essential plant oils concentrations $(1,2$, and $4 \%$ ), then planted per each plot at the recommended spacing $10 \mathrm{~cm} \mathrm{X} 10 \mathrm{~cm}$, within each row. Also, bacterial suspensions were applied as a soil drench at the 7 and 15 days from planting. Onion transplants were planted on the first week of December, approximately 90 plants / row. The recommended agricultural practices and irrigation for onion crop were followed. The experiment was arranged in completely randomized block design with four replicates. Disease assessment recorded as previously mentioned.

\section{Statistical analysis}

The data were statistically analyzed by analysis of variance (ANOVA) using the Statistical Analysis software "COStat 6.4" (CoStat, 2005). Means were separated by the least significant difference (LSD) test at $\mathrm{P}<0.05$ and $\mathrm{P}<0.01$ level.

\section{Results}

\section{Chemical analysis of tested essential plant oils}

The active components in the tested essential plant oils (Tables 1,2 and 3) indicate the presence of fifteen fractions in cardamom, twenty eight fractions in cumin, and twenty two fractions in thyme.

\section{Effect of essential plant oils on the linear growth of $\boldsymbol{S}$. terrestris :}

This study was conducted to evaluate the effects of essential plant oils at six concentrations $(0.25 \%, 0.50 \%, 1 \%, 2 \%, 4 \%$ and $8 \%)$ on the linear growth of different $S$. terrestris isolates which isolated from different locations (Fayoum, Sharkia and Nobaria) Data in Table (4) clearly revealed that, linear growth was significantly reduced by the tested essential plant oils treatments. In this respect, Fayoum isolate recorded the highest reduction of linear growth while, Nobaria isolate was the least affected with essential plant oils.

Increasing the concentration of tested essential plant oils led to an increase in linear growth reduction. Thyme oil was the most effective followed by cumin oil while cardamom oil recorded the least inhibition of the three isolates tested. On the other hand, there are no significant effect between oil concentration at $4 \%$ and $8 \%$ with most of tested essential plant oils (Table 4 ).

Table 1: The relative concentration of active components in cardamom oil

\begin{tabular}{cccl}
\hline Peak & Rt & Relative conc. & Compound name \\
\hline $\mathbf{1}$ & 7.617 & 2.59 & Alpha-pinene \\
$\mathbf{2}$ & 10.358 & 24.53 & 1,8-cineole \\
$\mathbf{3}$ & 13.173 & 1.32 & Gamma-terpinene \\
$\mathbf{4}$ & 13.465 & 3.68 & Alpha- Terpinolene \\
$\mathbf{5}$ & 16.787 & 21.6 & Terpinyl acetate \\
$\mathbf{6}$ & 21.064 & 6.5 & 6,11-Dimethyl-2,6,10-dodecatrien-1-01 \\
$\mathbf{7}$ & 21.344 & 2.69 & Alpha-Terpinenyl acetate \\
$\mathbf{8}$ & 21.808 & 2.97 & 4(5)-acetyl-2-(2-propyl)-1H-imidazole \\
$\mathbf{9}$ & 22.048 & 4.77 & Beta-selinene \\
$\mathbf{1 0}$ & 22.855 & 5.04 & 1,2-Ethanediol,1,2-dimyrtenyl-(E)-3(10)-caewn-2-ol \\
$\mathbf{1 1}$ & 23.141 & 7.24 & Nerolidol \\
$\mathbf{1 2}$ & 23.616 & 2.73 & Beta-Gurjunene \\
$\mathbf{1 3}$ & 24.8 & 6.33 & 5-Aminoindazole \\
$\mathbf{1 4}$ & 25.435 & 1.14 & 2-pentene,2-methyl \\
$\mathbf{1 5}$ & 25.556 & 2.78 & Farnesol Isomer B \\
\hline & Total & 95.91 & \\
\hline
\end{tabular}


Table 2: The relative concentration of active components in cumin oil

\begin{tabular}{cccl}
\hline Peak & Rt & relative conc. & Compound name \\
\hline $\mathbf{1}$ & 7.611 & 2.66 & Alpha-pinen \\
$\mathbf{2}$ & 8.968 & 2.6 & Pinene \\
$\mathbf{3}$ & 16.418 & 18.95 & Beta-cumic aldehyde \\
$\mathbf{4}$ & 20.457 & 2.21 & Beta-metha-1,4-dien-7-01 \\
$\mathbf{6}$ & 21.55 & 2.45 & 1,4-Benzenediamine \\
$\mathbf{7}$ & 21.865 & 2.5 & Myrtenal \\
$\mathbf{9}$ & 22.5 & 3.76 & Benzenetganol ,alpha-methyl \\
$\mathbf{1 0}$ & 23.433 & 4.78 & Unknown \\
$\mathbf{1 1}$ & 24.056 & 5.47 & Carotol \\
$\mathbf{1 2}$ & 24.583 & 2.72 & 4-pyridinol, acetate (ester) \\
$\mathbf{1 3}$ & 24.806 & 2.28 & Daucol \\
$\mathbf{1 4}$ & 25.218 & 2.29 & Guaiol \\
$\mathbf{1 5}$ & 26.666 & 2.03 & Isopropyl-4-methyl \\
$\mathbf{1 6}$ & 27.244 & 2.37 & Phenol,2,5-dimethyl \\
$\mathbf{1 7}$ & 27.564 & 4.43 & Coumarin \\
$\mathbf{1 8}$ & 28.954 & 2.48 & Unknown \\
$\mathbf{1 9}$ & 29.269 & 2.6 & Cembrene \\
$\mathbf{2 0}$ & 29.63 & 2.37 & 2,5-Dimethylhydroquinone \\
$\mathbf{2 1}$ & 29.973 & 4.39 & 1-butenyl-thiophene \\
$\mathbf{2 2}$ & 30.682 & 3.12 & Preclathridine A \\
$\mathbf{2 3}$ & 31.123 & 3.85 & Phenathrenemethanol \\
$\mathbf{2 4}$ & 31.649 & 2.07 & 2-pyridylacetamide \\
$\mathbf{2 5}$ & 31.85 & 2.9 & Alpha-terpinyl propinate-gamma-terpinene \\
$\mathbf{2 6}$ & 32.01 & 2.54 & E,E-Alpha- farnesene \\
$\mathbf{2 7}$ & 32.256 & 2.48 & E,E-Alpha- farnesene \\
$\mathbf{2 8}$ & 34.219 & 3.95 & 2-hydroxyphenyl \\
& Total & 94.25 & \\
\hline
\end{tabular}

The major components in cumin oil were Beta-cumic aldehyde, in thyme oil were 1,8-cineol and phenol 1- methylethyl. While, the major components in cardamom oil were 1, 8-cineole and terpinyl acetate.

Table 3: The relative concentration of active components in thyme oil

\begin{tabular}{cccl}
\hline Peak & $\mathbf{R t}$ & relative conc. & Compound name \\
\hline $\mathbf{1}$ & 6.662 & 0.7 & Alpha -pinene \\
$\mathbf{2}$ & 7.835 & 1.74 & Sabinene \\
$\mathbf{3}$ & 8.252 & 1.1 & 2-Beta-pinene \\
$\mathbf{4}$ & 9.465 & 25.11 & 1,8-cineol \\
$\mathbf{5}$ & 10.175 & 1.45 & Gamma-Terpinene \\
$\mathbf{6}$ & 11.445 & 4.42 & Linalool L \\
$\mathbf{7}$ & 13.248 & 0.36 & Borneol L \\
$\mathbf{8}$ & 13.476 & 2.02 & Terpinene-4-01 \\
$\mathbf{9}$ & 13.894 & 3.72 & Alpha terpineol \\
$\mathbf{1 0}$ & 15.096 & 1.21 & Cuminic \\
$\mathbf{1 1}$ & 15.227 & 1.3 & Linalyl acetate \\
$\mathbf{1 2}$ & 15.473 & 0.69 & Geraniol \\
$\mathbf{1 3}$ & 17.058 & 20.54 & Phenol 1- methylethyl \\
$\mathbf{1 4}$ & 17.665 & 14.5 & Aplpha -terpinenyl acetate \\
$\mathbf{1 5}$ & 18.077 & 0.21 & Carvacryl acetate \\
$\mathbf{1 6}$ & 18.214 & 0.63 & Geranyl acetate \\
$\mathbf{1 7}$ & 19.067 & 0.87 & Trans -caryophyllene \\
$\mathbf{1 8}$ & 20.497 & 0.56 & Tert- butylcatechin \\
$\mathbf{1 9}$ & 22.511 & 0.37 & Caryophllene oxide \\
$\mathbf{2 0}$ & 24.394 & 0.31 & Apiol \\
$\mathbf{2 1}$ & 29.607 & 16.17 & n-hexadecanoic acide \\
$\mathbf{2 2}$ & 31.077 & 0.75 & Linolieic acid methyl ester \\
& Total & 98.73 & \\
\hline
\end{tabular}


Table 4: Effect of different concentrations of tested essential plant oils on the linear growth of $S$. terrestris isolates

\begin{tabular}{|c|c|c|c|c|}
\hline \multirow{2}{*}{ Essential plant oils } & \multirow{2}{*}{ Conc. (\%) } & \multicolumn{3}{|c|}{ Linear growth of $S$. terrestris isolates } \\
\hline & & Sharkia & Fayoum & Nobaria \\
\hline \multirow{6}{*}{ Cardamom } & 0.25 & 5.6 & 5.2 & 6.1 \\
\hline & 0.50 & 4.5 & 4.1 & 4.9 \\
\hline & 1.0 & 3.7 & 3.5 & 4.6 \\
\hline & 2.0 & 3.5 & 3.2 & 4.2 \\
\hline & 4.0 & 3.2 & 2.9 & 3.9 \\
\hline & 8.0 & 3.0 & 2.7 & 3.8 \\
\hline \multirow{6}{*}{ Cumin } & 0.25 & 4.6 & 4.3 & 5.9 \\
\hline & 0.50 & 4.0 & 4.0 & 4.3 \\
\hline & 1.0 & 3.5 & 3.4 & 4.2 \\
\hline & 2.0 & 3.3 & 3.0 & 3.8 \\
\hline & 4.0 & 3.0 & 2.7 & 3.5 \\
\hline & 8.0 & 2.8 & 2.4 & 3.3 \\
\hline \multirow{6}{*}{ Thyme } & 0.25 & 3.6 & 3.3 & 3.8 \\
\hline & 0.50 & 3.2 & 2.9 & 3.4 \\
\hline & 1.0 & 2.7 & 2.4 & 2.9 \\
\hline & 2.0 & 2.5 & 2.2 & 2.8 \\
\hline & 4.0 & 2.2 & 2.1 & 2.5 \\
\hline & 8.0 & 2.1 & 2.0 & 2.2 \\
\hline \multicolumn{2}{|l|}{ Control } & 9.0 & 9.0 & 9.0 \\
\hline \multicolumn{5}{|l|}{ L.S.D. 1\%: } \\
\hline a) Treatment & $=$ & 0.22 & 0.20 & 0.18 \\
\hline b) Concentration & $1=$ & 0.27 & 0.25 & 0.23 \\
\hline (a) $\times($ b) & $=$ & 0.37 & 0.34 & 0.32 \\
\hline
\end{tabular}

2. Impact of transplant treatments with essential plant oils and soil application of $B$. subtilis on infection with $S$. terrestris under greenhouse condition.

\subsection{On onion pink root rot incidence:}

Data presented in Table (5) showed that, B. subtilis when applied as a soil drench combined with different concentrations of essential plant oils (dipping treatment) significantly decreased onion pink root rot incidence in most treatments compared with untreated control.

All tested essential plant oils at all concentrations showed significantly reduced incidence of onion pink root rot (\%) compared to non-treated control. Generally, thyme oils at $2 \%$ \& $4 \%$ followed by cumin at $4 \%$ with $B$. subtilis gave the highest percentage of healthy plants as well as the highest efficacy in reducing of onion pink root rot compared to other treatments. The presented data revealed that, there is a relationship between concentrations of tested essential plant oils and their effect on the incidence of onion pink root rots. Moreover, there is a positive significant relationship between application of $B$. subtilis with essential plant oils and increase treatments activity (Table 5).

\subsection{On onion fresh and dry weight:}

Results illustrated in Table (6) revealed that, all tested treatments and their combinations significantly increased onion fresh and dry weight. Fresh and dry weights were highly increased by applying $B$. subtilis with different treatments of essential plant oils.

Data also showed that, fresh and dry weight were affected significantly by increasing concentrations of essential plant oils (dipping treatments) from 0.5 to $4 \%$. The highest increase in fresh and dry weight of onion was obtained by thyme oil at $4 \%$ combined with $B$. subtilis treatment (Table $6)$. 
Table 5: Effect of transplant treatment with tested essential plant oils and soil application of $B$. subtilis on onion pink root rot disease under soil infestation with $S$. terrestris under greenhouse conditions.

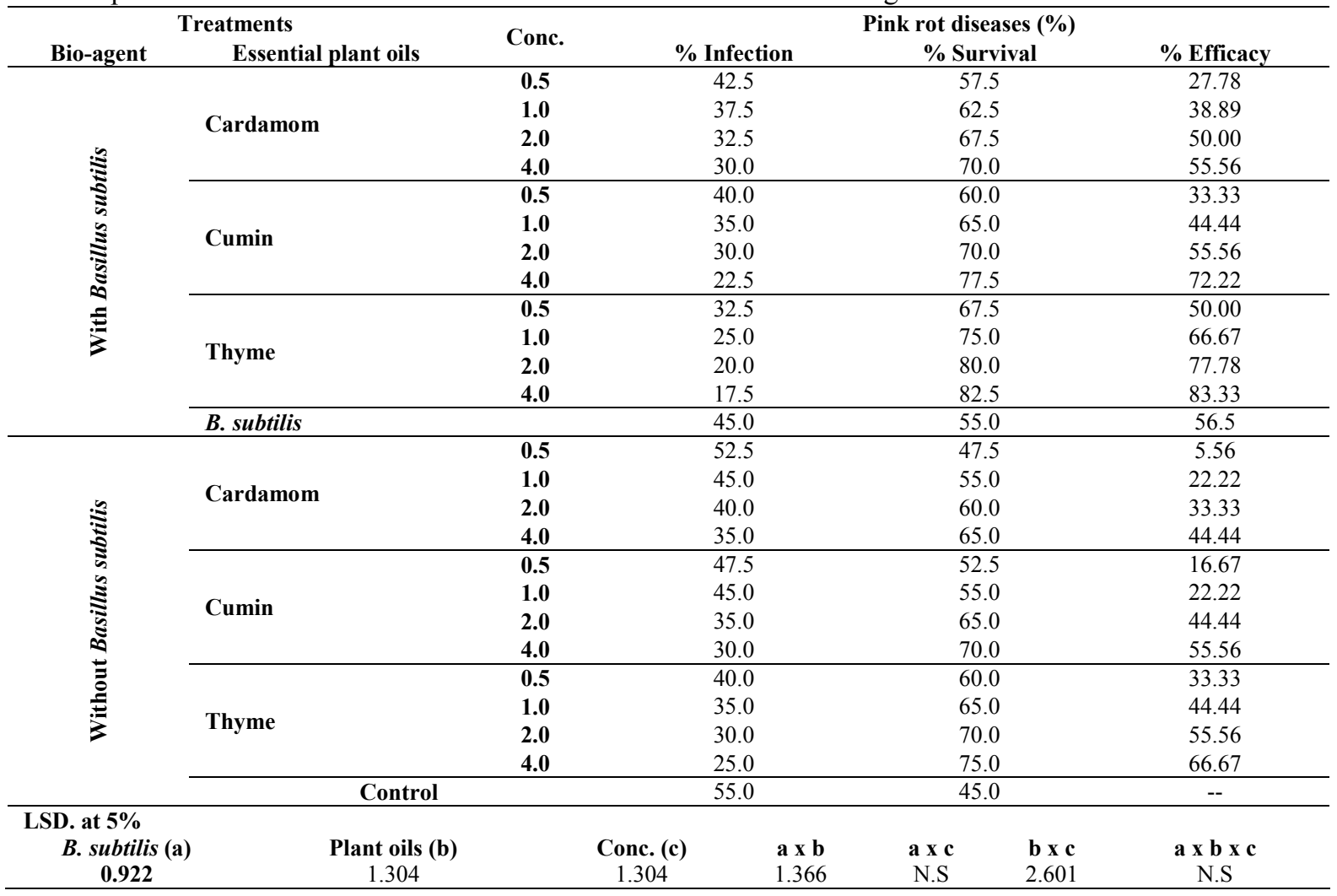

Table 6: Effect of transplant treatments with essential plant oils and soil application of B. subtilis on onion fresh and dry weight under soil infestation with S. terrestris.

\begin{tabular}{|c|c|c|c|c|c|c|c|}
\hline Tre & tments & Conc. & Fresh & Increase \% & Dry & & Increase \% \\
\hline B10-agent & Essential plant oils & & welght /g & & & & \\
\hline \multirow{13}{*}{ 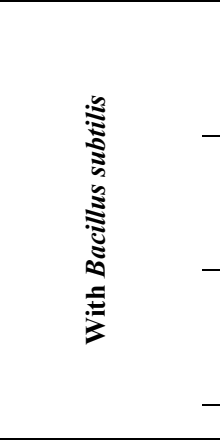 } & \multirow{4}{*}{ Cardamom } & 0.5 & 123.63 & 14.80 & 101.95 & & 24.77 \\
\hline & & 1.0 & 149.23 & 38.57 & 125.92 & & 54.11 \\
\hline & & 2.0 & 164.26 & 52.53 & 131.83 & & 61.34 \\
\hline & & 4.0 & 172.99 & 60.64 & 141.92 & & 73.69 \\
\hline & \multirow{4}{*}{ Cumin } & 0.5 & 132.14 & 22.70 & 119.65 & & 46.43 \\
\hline & & 1.0 & 157.39 & 46.15 & 128.85 & & 57.69 \\
\hline & & 2.0 & 170.77 & 58.58 & 138.44 & & 69.43 \\
\hline & & 4.0 & 177.80 & 65.10 & 146.53 & & 79.33 \\
\hline & \multirow{4}{*}{ Thyme } & 0.5 & 160.90 & 49.41 & 129.52 & & 58.51 \\
\hline & & 1.0 & 168.00 & 56.00 & 135.31 & & 65.60 \\
\hline & & 2.0 & 178.79 & 66.02 & 147.88 & & 80.98 \\
\hline & & 4.0 & 190.23 & 76.65 & 157.86 & & 93.20 \\
\hline & B. subtilis & 0.0 & 131.47 & 22.08 & 118.53 & & 45.06 \\
\hline \multirow{13}{*}{ 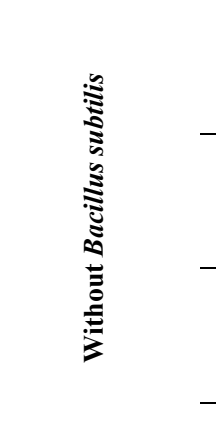 } & \multirow{4}{*}{ Cardamom } & 0.5 & 119.00 & 10.50 & 94.33 & & 15.44 \\
\hline & & 1.0 & 133.26 & 23.74 & 121.03 & & 48.12 \\
\hline & & 2.0 & 147.63 & 37.09 & 127.54 & & 56.09 \\
\hline & & 4.0 & 158.07 & 46.78 & 129.29 & & 58.23 \\
\hline & \multirow{4}{*}{ Cumin } & 0.5 & 123.69 & 14.86 & 103.98 & & 27.25 \\
\hline & & 1.0 & 138.12 & 28.26 & 122.99 & & 50.52 \\
\hline & & 2.0 & 153.14 & 42.20 & 127.77 & & 56.37 \\
\hline & & 4.0 & 169.16 & 57.08 & 136.06 & & 66.52 \\
\hline & \multirow{4}{*}{ Thyme } & 0.5 & 141.92 & 31.79 & 124.51 & & 52.38 \\
\hline & & 1.0 & 149.21 & 38.56 & 126.84 & & 55.23 \\
\hline & & 2.0 & 170.39 & 58.22 & 139.66 & & 70.92 \\
\hline & & 4.0 & 178.20 & 65.47 & 146.91 & & 79.79 \\
\hline & Control & 0.0 & 107.69 & 0.00 & 81.71 & & 0.00 \\
\hline LSD. at 5\% & B. subtilis (a) & \multicolumn{2}{|c|}{ Plant oils (b) } & Conc. (c) & a $\times c$ & b x c & $\mathbf{a} \times \mathbf{b} \times \mathbf{c}$ \\
\hline Fresh weight & 3.187 & \multicolumn{2}{|c|}{4.509} & 4.509 & 6.358 & 8.991 & 12.716 \\
\hline Dry weight & 2.685 & \multicolumn{2}{|c|}{3.798} & 3.798 & 5.356 & 7.575 & N.S \\
\hline
\end{tabular}




\section{Impact of transplant treatment with tested essential plant oils and soil application of $B$. subtilis under field conditions during seasons $2017 / 2018$ and 2018/2019.}

\subsection{On onion pink root rot:}

Data presented in Tables $(7 \& 8)$ illustrated that the effect of $B$. subtilis when application as a soil drench integrated with different concentrations of tested essential plant oils as dipping treatment were significantly effective for reducing pink root rot disease incidence in two successive seasons 2017/2018 and 2018/2019 compared with untreated control (without any treatment). Also, increasing the concentration of essential plant oils (from 0.0 to $4 \%$ ) was more and significantly effective for decreasing disease incidence.

Generally, thyme followed by cumin oils at $4 \%$ when used with $B$. subtilis gave the highest percentage of apparent healthy plants as well as the highest efficacy in reducing of onion pink root rots compared to other treatments (Tables $7 \& 8$ ).

As for the combination treatments, the obtained data from Tables $(7 \& 8)$ indicated that, the percentage of pink root rot incidence in two successive seasons were affected significantly by the interaction between $B$. subtilis and essential plant oils treatments. The results showed also that, there is a positive significant relationship between essential plant oils concentrations and their effect on the incidence of onion pink root rot as well as between application of $B$. subtilis with plant oils and increase treatments activity.

\subsection{On onion bulb yield:}

Data in Table (9) revealed that, the most of treatments significantly increased onion bulb yield (kg/plot) in the two seasons 2017/2018 and 2018/2019. Moreover, applying of B. subtilis with the essential plant oils at different concentrations led to a significant effect for increasing onion bulb yield than without B. subtilis. Also, increasing concentration of essential tested plant oils (from 0.0 to $4 \%$ ) gave more significantly effective for increasing onion bulb yield.

In this respect, the best treatments were obtained when combined between $B$. subtilis and thyme at $4 \%$ followed by B. subtilis and cumin at 4\% during the two growing seasons 2017/2018 and 2018/2019 (Table 9).

Table 7: Effect of transplant treatment with essential plant oils and soil application of $B$. subtilis on onion pink root rot incidence under field conditions during season 2017/2018.

\begin{tabular}{|c|c|c|c|c|c|}
\hline \multicolumn{2}{|c|}{$\begin{array}{l}\text { Treatments } \\
\end{array}$} & \multirow{2}{*}{ Conc. } & \multicolumn{3}{|c|}{ Pink rot diseases (\%) } \\
\hline Bio-agent & Essential plant oils & & $\%$ Infection & $\%$ Survival & $\%$ Efficacy \\
\hline \multirow{10}{*}{ 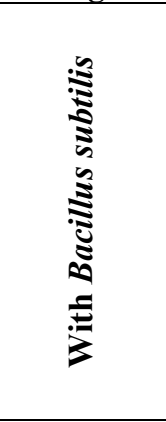 } & \multirow{3}{*}{ Cardamom } & $\mathbf{1 . 0}$ & 28.3 & 71.7 & 30.47 \\
\hline & & 2.0 & 22.5 & 77.5 & 44.72 \\
\hline & & 4.0 & 18.4 & 81.6 & 54.79 \\
\hline & \multirow{3}{*}{ Cumin } & $\mathbf{1 . 0}$ & 26.6 & 73.4 & 34.64 \\
\hline & & 2.0 & 21.6 & 78.4 & 46.93 \\
\hline & & 4.0 & 16.2 & 83.8 & 60.20 \\
\hline & \multirow{3}{*}{ Thyme } & 1.0 & 19.3 & 80.7 & 52.58 \\
\hline & & 2.0 & 16.8 & 83.2 & 58.72 \\
\hline & & 4.0 & 14.2 & 85.8 & 65.11 \\
\hline & B. subtilis & 0.0 & 33.5 & 66.5 & 17.69 \\
\hline \multirow{10}{*}{ 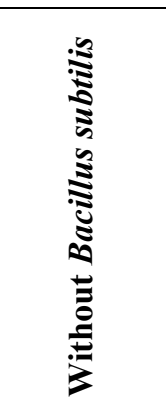 } & \multirow{3}{*}{ Cardamom } & 1.0 & 31.9 & 68.1 & 21.62 \\
\hline & & 2.0 & 26.2 & 73.8 & 35.63 \\
\hline & & 4.0 & 21.6 & 78.4 & 46.93 \\
\hline & \multirow{3}{*}{ Cumin } & 1.0 & 30.5 & 69.5 & 25.06 \\
\hline & & 2.0 & 23.8 & 76.2 & 41.52 \\
\hline & & 4.0 & 19.3 & 80.7 & 52.58 \\
\hline & \multirow{3}{*}{ Thyme } & 1.0 & 24.9 & 75.1 & 38.82 \\
\hline & & 2.0 & 19.8 & 80.2 & 51.35 \\
\hline & & 4.0 & 17.6 & 82.4 & 56.76 \\
\hline & Control & 0.0 & 40.7 & 59.3 & 0.00 \\
\hline $\begin{array}{c}\text { LSD. at } 5 \% \\
2017 / 2018 \\
\end{array}$ & $\begin{array}{c}\text { B. subtilis (a) } \\
0.371\end{array}$ & $\begin{array}{c}\text { Plant oils (b) } \\
0.525\end{array}$ & $\begin{array}{c}\text { Conc. (c) } \\
0.454\end{array}$ & $\begin{array}{cc}\mathbf{a ~ x ~ b} & \mathbf{a ~ x ~ c} \\
0.742 & 0.642\end{array}$ & $\begin{array}{c}\mathbf{a} \times \mathbf{~ b} \mathbf{x} \mathbf{c} \\
1.284\end{array}$ \\
\hline
\end{tabular}


Table 8: Effect of transplant treatment with essential plant oils and soil application of $B$. subtilis on onion pink root rot disease under field conditions during season 2018/2019.

\begin{tabular}{|c|c|c|c|c|c|c|}
\hline \multicolumn{2}{|c|}{ Treatments } & \multirow{2}{*}{ Conc. } & \multicolumn{4}{|c|}{ Pink rot diseases (\%) } \\
\hline Bio-agent & Essential plant oils & & $\%$ Infection & \% Survival & & $\%$ Efficacy \\
\hline \multirow{10}{*}{ 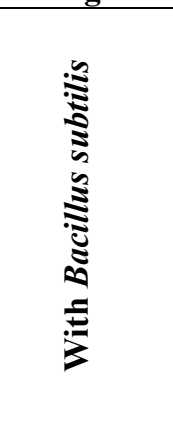 } & \multirow{3}{*}{ Cardamom } & 1.0 & 32.5 & 67.5 & & 35.64 \\
\hline & & 2.0 & 26.8 & 73.2 & & 46.93 \\
\hline & & 4.0 & 21.0 & 79 & & 58.42 \\
\hline & \multirow{3}{*}{ Cumin } & 1.0 & 29.6 & 70.4 & & 41.39 \\
\hline & & 2.0 & 24.8 & 75.2 & & 50.89 \\
\hline & & 4.0 & 19.1 & 80.9 & & 62.18 \\
\hline & \multirow{3}{*}{ Thyme } & 1.0 & 28.3 & 71.7 & & 43.96 \\
\hline & & 2.0 & 22.3 & 77.7 & & 55.84 \\
\hline & & 4.0 & 17.6 & 82.4 & & 65.15 \\
\hline & B. subtilis & 0.0 & 35.3 & 64.7 & & 30.10 \\
\hline \multirow{10}{*}{ 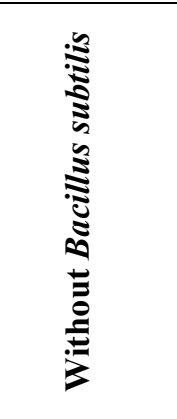 } & \multirow{3}{*}{ Cardamom } & 1.0 & 40.9 & 59.1 & & 19.01 \\
\hline & & 2.0 & 34.5 & 65.5 & & 31.68 \\
\hline & & 4.0 & 25.6 & 74.4 & & 49.31 \\
\hline & \multirow{3}{*}{ Cumin } & 1.0 & 36.1 & 63.9 & & 28.51 \\
\hline & & 2.0 & 27.6 & 72.4 & & 45.35 \\
\hline & & 4.0 & 24.8 & 75.2 & & 50.89 \\
\hline & \multirow{3}{*}{ Thyme } & 1.0 & 29.4 & 70.6 & & 41.78 \\
\hline & & 2.0 & 24.9 & 75.1 & & 50.69 \\
\hline & & 4.0 & 21.6 & 78.4 & & 57.23 \\
\hline & Control & 0.0 & 50.5 & 49.5 & & 0.00 \\
\hline $\begin{array}{r}\text { LSD. at 5\% } \\
2018 / 2019\end{array}$ & $\begin{array}{c}\text { B. subtilis (a) } \\
0.460\end{array}$ & $\begin{array}{c}\text { Plant oils (b) } \\
0.695\end{array}$ & $\begin{array}{c}\text { Conc. (c) } \\
0.602\end{array}$ & $\begin{array}{l}\mathbf{a} \times \mathbf{c} \\
0.850\end{array}$ & $\begin{array}{l}\mathbf{b} \mathbf{x} \mathbf{c} \\
1.701\end{array}$ & $\begin{array}{c}\mathbf{a} \times \mathbf{x} \times \mathbf{~ c} \\
1.701\end{array}$ \\
\hline
\end{tabular}

Table 9: Effect of transplant treatment with essential plant oils and soil application of $B$. subtilis on onion bulb yield kg/plot under field conditions during seasons 2017/2018 and 2018/2019.

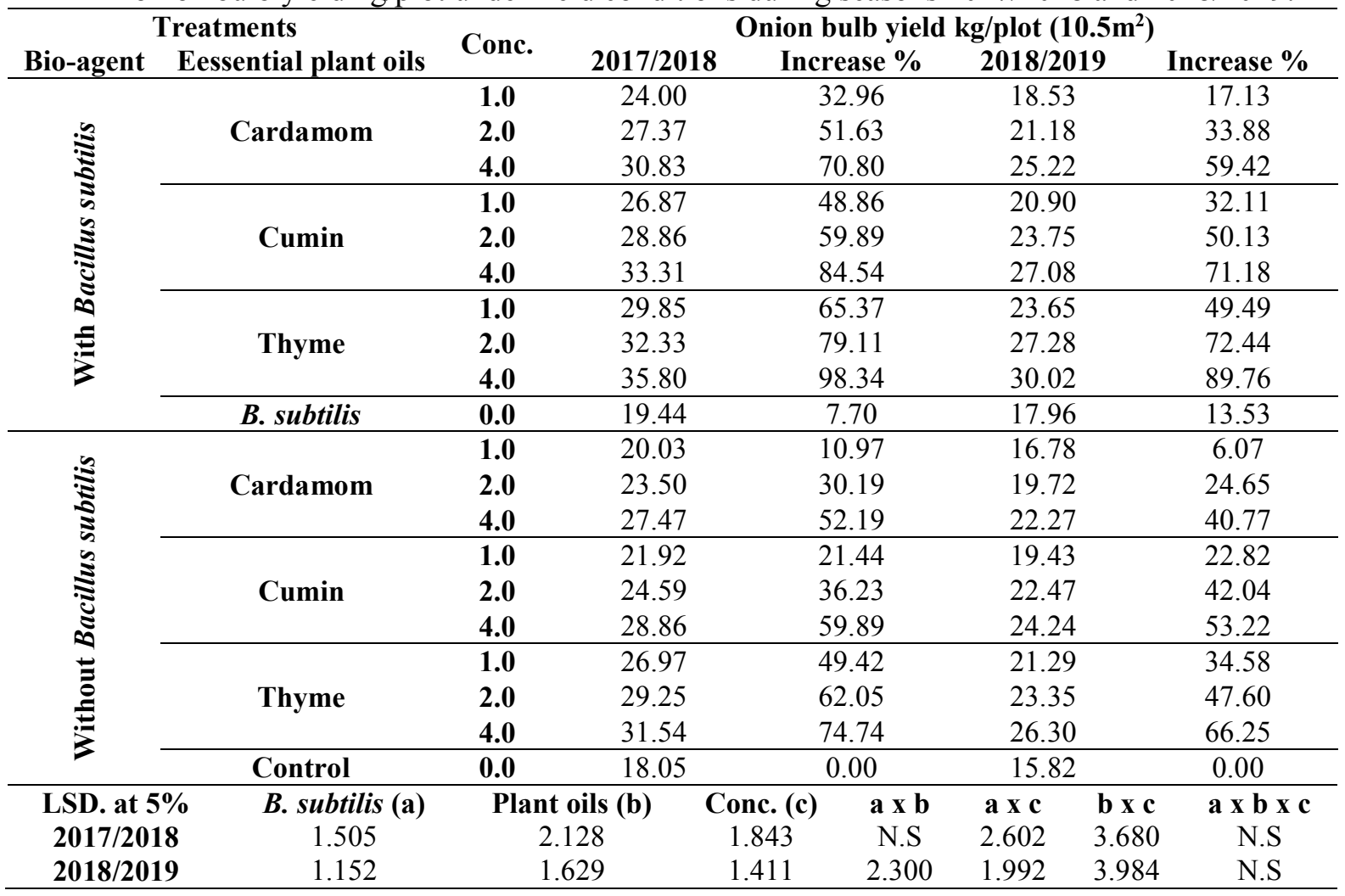




\section{Discussion}

In the present study, using of Bacillus subtilis (as soil treatment) in combinations with different concentrations of tested essential plant oils (as transplants dipping treatment) were effective for reducing incidence of pink root rot under artificial and natural infections in greenhouse and field trials, compared with untreated control (without any treatment). This is in agreement with various investigators (El-Hadidy, 2003, El-Moshtohory, 2007, Mahmoud et al., 2013, Mahmoud 2014, Mahmoud and Gomaa, 2015, Ahmed et al., 2019, Omar and Kordali, 2019 and Zhansheng et al., 2019), who reported that, $B$. subtilis and essential plant oils play an important role in reducing of many plant disease.

Bacillus subtilis considered one of the plant growth-promoting rhizobacteria (PGPR), which suppress a variety of root and vascular disease caused by soil-borne pathogens (Mishra et al., 2013, Mahmoud, 2014, Ahmed et al., 2019 and Zhansheng et al., 2019). Awais et al., (2010) stated that, the biocontrol activity of $B$. subtilis had been associated with the production of certain products such as enzymes, phenazines, pio-compounds, indole derivatives, and antibiotic i.e. moenomycins, difficidins, bacillomycins and bacillaenes. In the present study, using Bacillus subtilis when applied as soil treatment was effective for reducing incidence of pink rot under artificial and natural infections in greenhouse and field trials, compared with untreated control (without any treatment). This is in agreement with various investigators (El-Hadidy, 2003, Mishra et al., 2013, Mahmoud, 2014, Ahmed et al., 2019 and Zhansheng et al., 2019), who reported that, B. subtilis play an important role in reducing of many plant diseases.

Essential oils (also called volatile oils) are natural, complex, aromatic, oily liquids and composed mainly of terpenes, in addition to some other non-terpene components. They have been shown to possess antibacterial, antifungal, antiviral, insecticidal, and antioxidant properties (Coutinho et al., 2010). Essential oils have been known to possess antimicrobial activity by their action through the disruption of the cell membrane (Lixandru et al., 2010). Moreover, Burt (2004) illustrated that, the hydrophobicity of essential oils enables them to affect the lipids of the cell membrane and mitochondria, rendering them permeable and leading to leakage of cell contents. On the other hand, inhibitory action of natural products on moulds involves cytoplasm granulation, cytoplasmic membrane rupture and inactivation and/or inhibition of intercellular and extracellular enzymes. These biological events could take place separately or concomitantly culminating with inhibition of mycelium growth or spore germination (Abdolmaleki et al., 2008 and Omar and Kordali, 2019). Generally in many cases, the antifungal activity of the essential plant oils results from the interaction between the different classes of compounds such as phenols, aldehydes, ketones, alcohols, esters, ethers or hydrocarbons present in these oils. Several studies have found that a number of these compounds exhibited significant antifungal properties when tested separately (Burt 2004 and Nestor Bassole and Juliani, 2012). This was clearly demonstrated with our results, which indicated that, linear growth of study pathogen was significantly reduced by most tested essential plant oils treatments compared with control. This might be attributed to the content of essential plant oils constituents with antimicrobial activity such as, tannins, glycosides, and resins, which can be found in certain spices such as cumic aldehyde and pyridine in cumin, 1,8cineol and phenol 1-methylethyl in thyme oil and 1,8-cineole and terpinyl acetete in cardamom which showed clearly in GC-MASS analysis this in agreement with Segvi'c Klari'c et al., (2007) showed that p-cymene (36.5\%), and 1,8-cineole (11.3\%) were the main components of thyme essential oil. While, the major components in cardamom oil were 1, 8-cineole (15\%) and terpinyl acetate $(23 \%)$ (ElMoshtohory, 2007). Asghari-Marjanlo et al., (2009) and Akash et al., (2018) also determined p-cymene $(12.9 \%)$ and cumin aldehyde $(24.9 \%)$ to be the major components of cumin oil which have antifungal activity, enabling them to provide protection of fruit and vegetables against quantitative and qualitative losses, thereby enhancing their shelf-life (Kedia et al., 2018).

The results also indicated that the tested essential plant oils at different concentrations significantly reduced onion pink root rot as well increasing of plant growth of (fresh and dry) bulb yield which grown under greenhouse and field conditions, compared to non-treated control. Data also showed that, there was a relation between essential plant oil concentrations and their effect on the pathogen and studied disease. This is agreement with many investigators (El-Moshtohory, 2007, and Mahmoud et al., 2013) who stated that, the essential plant oils are rich of bioactive chemicals, which have biological activities such as antimicrobial. 


\section{Reference}

Abdolmaleki M., M. Salari, S. Bahraminejad, N. Panjeke and S. Abbasi, 2008. Antifungal effects of Cinnamomum zeylanicum extract on growth of Rhizoctonia solani, Phytophthora oxysporum, Fusarium drechsleri, Bipolaris sorokiniana. Plant Pathol., 44:255-261

Ahmed M., F.H. Ali and J.D. Nada 2019. Ability of creative of bioformulations using Bacillus subtilis for biological control of some plant disease fungi. Journal of Research on the Lepidoptera, 50 (4):17-24

Akash, K., B. Prakash, K. Prashant, and N.K. Dubey, 2018. Antifungal and antiaflatoxigenic properties of Cuminum cyminum (L.) seed essential oil and its efficacy as a preservative in stored commodities. Inter. J. Food Microbiol., 3: 1-7

Asghari-Marjanlo, A., Y. Mostofi, S.H. Shoeibi, and M. Fattahi, 2009. Effect of cumin essential oil on postharvest decay and some quality factors of strawberry. J. Med. Pl., 8, 25-43.

Awais, M., A. Pervez, A. Yaqub and M.M. Shah, 2010. Production of antimicrobial metabolites by Bacillus subtilis immobilized in polyacrylamide gel Pakistan J. Zool., 42(3): 267-275

Basyony, A.E., A.H. Ashub, and F.A. Epad, 1989. .Effect of plant population and nitrogen levels on rapeseed oil quality and quantity. Annal Agric. Sci. Moshtohor, 27:761-770.

Burt, S., 2004. Essential oils: their antibacterial properties and potential applications in foods - a review. Int. J. Food Microbiol., 94(3):223-253.

Callan, N. W., D.E. Mather and J.B. Miller, 1990. Biopriming seed treatment for biological control of Pythium ultimum pre-emergence damping-off in sh 2 sweet corn. Plant Dis., 74: 368-372.

CoStat, 2005. CoStat program, version 6.4. CoHort software, Monterey, CA, USA.

Coutinho, H.D.M., E.F. Matias, K.A. Santos, S.R. Tintino, C.E.S. Souza, G.M.M. Guedes, F.A.D. Santos, J.G.M. Costa, V.S. Falcao-Silva, and J.P. Siqueira-Junior, 2010. Enhancement of the norfloxacin antibiotic activity by gaseous contact with the essential oil of Croton zehntneri. Pharmacognosy., 2(4):362-364.

EL-Bastawesy, A.M. and R.H. Mohamed, 2005. Evaluation of Thyme oil role as antimicrobial, anticarcenogenic and anti-inflammatory agents. Egypt. J. Agric. Res., 83 (2):789-809.

El-Hadidy, A.M., 2003. New approaches for controlling some soil borne fungal pathogens on pepper in reclaimed soil. Ph.D. Thesis, Fac. Agric. Ain Shams Univ., 169.

El-Moshtohory, T.A., 2007. Chemical and microbiological studies on some essential oils. Ph.D. Thesis, Fac. of Agric. Moshtohor, Benha Univ., 152.

Hovius, M.H.Y. and I.L. Goldman, 2004. Evaluation of long-day onions for resistance to pink rot infection using greenhouse and laboratory techniques. J. Amer. Soc. Hort. Sci., 129(2):258265.

Kapoor I.P.S., B. Singh, G. Singh, V.B. Isidorov, and L. Szczepaniak, 2008. Chemistry, antifungal and antioxidant activities of cardamom (Amomum subulatum) essential oil and oleoresins. International Journal of Essential Oil Therapeutics, 2: 29-40

Kedia, A., B. Prakash, P.K. Mishra, and N.K. Dubey, 2018. Antifungal and antiaflatoxigenic properties of Cuminum cyminum (L.) seed essential oil and its efficacy as a preservative in stored commodities. Int. J. Food Microbiol., 168-169, 1-7.

Kim, Y.K., S.B. Lee, H.S. Shim, C.J. Lee, and H.D. Kim, 2003. Pink root of onions caused by Pyrenochaeta terrestris (syn. Phoma terrestris). The Plant Pathology Journal, 19:195-199.

Lixandru B.E., N.O. Dracea, C.C. Dragomirescu, E.C. Dragulescu, I.L. Coldea, L. Anton, E. Dobre, C. Rovinaru, and I. Codita 2010. Antimicrobial activity of plant essential oils against bacterial and fungal species involved in food poisoining and/or food decay. Roum Arch Microbiol Immunol., 69(4):224-230.

Mahmoud, E.Y., 2014. Performance of some antagonistic bacteria in minimizing occurrence of peanut damping - off, root and pod rot diseases. Egypt j. Phytopathol., 42 (1):205-220.

Mahmoud, E.Y., and M.A. Gomaa, 2015. Impact of some essential plant oils for controlling of peanut pod rots diseases and aflatoxin. J. Biol. Chem. \& Envirom. Sci., 10 (1): 261-280.

Mahmoud, E.Y., M.M. Ibrahim, and T.A.A. Essa, 2013. Efficacy of plant essential oils in controlling damping-off and root rots diseases of peanut as fungicides alternative. Journal of Applied Sciences Research, 9(3): 1612-1622. 
Mohamed-Hala, A., 2018. Integrated control of onion pink and basal rot diseases. Ph.D. Thesis Fac. of Agric. Moshtohor Benha Univ., 138 pp.

Mishra D.S., A. Kumar, S.E. Prajapati, A.K. Singh, and S.D. Sharma, 2013. Identification of the compatible bacterial and fungal isolates and their effectiveness against plant diseases. Journal of Environmental Biology, 34 (3):183-189.

Nestor Bassole, H., and R. Juliani, 2012. Essential oils in combination and their antimicrobial properties. Molecules 17, 3989-4006, http://dx.doi.org/10. 3390/molecules17043989.

Omar, M.S. and Ş. Kordali, 2019. Review of essential oils as antifungal agents for plant fungal diseases. Ziraat Fakültesi Dergisi, 14 (2):294-301.

Omidbaigi R., M. Yahyazadeh, R. Zare and H. Taheri 2007. The In Vitro Action of Essential Oils on Aspergillus flavus. Journal of essential oil-bearing plants JEOP., 10 (1): 46 - 52

Pawar, V.C. and V.S. Thaker, 2007. Evaluation of the anti-Fusarium oxysporum f. sp. cicer and antiAlternaria porri effects of some essential oils. World Journal of Microbiology \& Biotechnology, 23: 1099-1106

Sameza, M.L., L.C. Mabou, S.N. Tchameni, M.A. Bedine, F. Tchoumbougnang, P.M. Dongmo and F.B. Fekam 2016. Evaluation of clove essential oil as a mycobiocide against Rhizopus stolonifer and Fusarium solani, Tuber Rot Causing Fungi in Yam (Dioscorea rotundata Poir.). Journal of Phytopathology, 164: 433-440.

Segvi'c K.C., M. Kosalec, I. Masteli, J. Pieckova, and E.S. Pepeljnak 2007. Antifungal activity of thyme (Thymus vulgaris L.) essential oil and thymol against moulds from damp dwellings. Lett. Appl. Microbiol. 44:36-42.

Thabet, M. and W. Khalifa 2018. Antifungal activities of clove oil against root rot and wilt pathogens of tomato plants. J. Agric. \& Environ. Sci., 18(3):105-114.

Watson, R.D., 1961. Rapid identification of the onion pink-root fungus. Plant Dis. Rptr. 45:289.

Zhansheng, Wu. , H. Yuanyuan, L. Yan, D. Jiawei, L. Xiaochen and L. Chun, 2019. Biocontrol of Rhizoctonia solani via induction of the defense mechanism and antimicrobial compounds produced by Bacillus subtilis SL-44 on Pepper (Capsicum annuum L.). Front. Microbiol., 10:112. 